\title{
PENGARUH TEKANAN WAKTU, PROSEDUR REVIEW DAN KONTROL KUALITAS, KOMITMEN PROFESIONAL, DAN EXTERNAL LOCUS OF CONTROL TERHADAP PENGHENTIAN PREMATUR ATAS PROSEDUR AUDIT
}

\author{
Aang Syahdina \\ Pohinia Kinima \\ Sekolah Tinggi Ilmu Ekonomi Y.A.I \\ aangsyahdina@ymail.com
}

\begin{abstract}
Information disclosure in financial statements is part of the accountability and transparency of the Regional Government Financial Statements to the public. This study aims to determine the effect of the characteristics of local government, total population, audit findings, and audit opinions on disclosure of financial statements. The population in this study was the district / city local government in the province of Central Java in 2015-2017. The sample in this study was selected by saturated sampling, and the data obtained were 105 financial statements of local governments. The analysis technique used in this study is multiple linear regression analysis. The results of the study prove that the official age of the government and audit opinion variables have a significant influence on the disclosure of local government financial statements, while the size of local government, total population, and audit findings variables do not have a significant impact on LGFR disclosure.
\end{abstract}

Keyword : government characteristics, audit findings, audit opinion and financial statement disclosures

\begin{abstract}
ABSTRAK: Keterbukaan informasi dalam laporan keuangan adalah bagian dari pertanggungjawaban dan transparansi Laporan Keuangan Pemerintah Daerah kepada publik. Penelitian ini bertujuan untuk mengetahui pengaruh karakteristik pemerintah daerah, total populasi, temuan audit, dan opini audit terhadap pengungkapan laporan keuangannya. Populasi dalam penelitian ini adalah pemerintah daerah kabupaten / kota di provinsi Jawa Tengah pada tahun 2015-2017. Sampel dalam penelitian ini dipilih dengan sampling jenuh, dan data yang diperoleh adalah 105 laporan keuangan pemerintah daerah. Teknik analisis yang digunakan dalam penelitian ini adalah analisis regresi linier berganda. Hasil penelitian membuktikan bahwa usia resmi pemerintah dan variabel opini audit memiliki pengaruh signifikan terhadap pengungkapan laporan keuangan pemerintah daerah, sedangkan ukuran pemerintah daerah, total populasi, dan variabel temuan audit tidak memiliki dampak signifikan terhadap pengungkapan LGFR.
\end{abstract}

Kata kunci: karakteristik pemerintah, temuan audit, opini audit, dan laporan keuangan pengungkapan

\section{Pendahuluan}

Kualitas audit merupakan suatu hal yang penting yang harus diperhatikan oleh auditor. Untuk menghasilkan laporan audit yang berkualitas baik, seorang auditor harus melaksanakan prosedur audit sesuai dengan standar audit yang berlaku umum (SPAP). Namun dalam pelaksanaan sesungguhnya dilapangan, terdapat berbagai perilaku auditor yang dapat menyebabkan penurunan kualitas laporan audit yang dihasilkan. 
Salah satu bentuk perilaku yang menyebabkan berkurangnya kualitas audit adalah penghentian prematur atas prosedur audit (Coram et al; 2004). Terdapat banyak faktor yang menjadi alasan bagi auditor untuk menghentikan prosedur audit yang akan dilaksanakan, berbagai faktor tersebut dapat disebabkan oleh faktor internal (karakteristik personal auditor) maupun faktor eksternal (faktor situasional) (Weningtyas dalam Wahyudi dkk., 2011). Faktor internal yang mempengaruhi penerimaan penyimpangan perilaku dalam audit terdiri dari locus of control, self rate employee performance, turnover intentions, dan self esteem in relation to ambition (Kartika dan Wijayanti; Irawati dan Mukhlasin; Donelly, Quirin, dan O’Bryan dalam Safriliana dkk., 2016). Sedangkan faktor eksternal yang dapat menyebabkan kemungkinan terjadinya penghentian prematur atas prosedur audit meliputi time pressure, resiko audit, materialitas, serta prosedur review dan kontrol kualitas oleh Kantor Akuntan Publik (Weningtyas dalam Wahyudi dkk., 2011).

Time pressure (tekanan waktu) merupakan kondisi dimana auditor mendapat tekanan dari Kantor Akuntan Publik tempatnya bekerja untuk menyelesaikan pekerjaan audit pada waktu dan anggaran biaya yang telah ditetapkan sebelumnya. Tekanan waktu yang diberikan oleh Kantor Akuntan Publik kepada auditornya bertujuan untuk mengurangi biaya audit karena semakin cepat waktu pengerjaan audit, maka semakin kecil biaya pelaksanaan audit yang akan dikeluarkan (Nurhardianty, 2016). Agar menepati

Selain komitmen profesional, locus of control adalah faktor lainnya yang mendasari auditor melakukan penghentian prematur atas prosedur audit. Locus of control adalah seberapa besar keyakinan seseorang pada dirinya sendiri dalam menentukan nasibnya (Robbins dalam Wintari, 2015). Locus of anggaran waktu yang telah ditetapkan, ada kemungkinan bagi auditor untuk melakukan pengabaian terhadap prosedur audit bahkan pemberhentian prosedur audit.

Untuk mengontrol penghentian dini dari pelaksanaan atas prosedur audit, kantor akuntan publik harus menyediakan prosedur review yang mampu mendeteksi sukses atau gagalnya auditor dalam melaksanakan seluruh tugas yang ditetapkan. Prosedur review yang tersusun dengan baik dan kontrol kualitas yang terus menerus akan meningkatkan kemungkinan terdeteksinya kecurangan yang dilakukan oleh auditor yang dapat berupa perilaku pengurangan kualitas audit (Sumekto dalam Wahyudi dkk., 2011).

Selain faktor eksternal, praktik penghentian prematur atas prosedur audit juga dipengaruhi oleh faktor internal seperti komitmen profesional dan locus of control. Komitmen profesional adalah tingkat loyalitas individu pada profesinya seperti yang dipersepsikan oleh individu tersebut (Trisnaningsih, 2003). Tenaga profesional sudah dididik untuk menjalankan tugas-tugas yang kompleks secara independen dan menyelesaikan masalah dengan menggunakan keahlian dan dedikasi secara profesional (Nurhardianty, 2016). Komitmen profesional dapat menjadi faktor penyebab terjadinya penghentian prematur atas prosedur audit. Jika seorang auditor semakin berkomitmen terhadap profesinya dan selalu menjaga integritasnya, maka auditor tersebut akan berpikir untuk melakukan hal tersebut, karena akan mencoreng integritas dan profesionalnya apalagi jika diketahui oleh rekannya (Rikarbo, 2012).

control seseorang dibedakan atas kecenderungan sudut pandang seseorang yaitu locus of control eksternal dan locus of control internal. Lokus kendali seseorang akan mempengaruhi cara pandang mereka terhadap kondisi yang dihadapi. Auditor yang memiliki lokus kendali internal, cenderung memiliki 
motivasi kuat dalam penyelesaian masalah jika dibandingkan dengan seseorang yang memiliki lokus kendali eksternal. Auditor yang memiliki lokus kendali eksternal diduga cenderung melakukan penghentian prematur atas prosedur audit. Berdasarkan latar belakang tersebut, maka peneliti termotivasi untuk melakukan penelitian dengan judul "Pengaruh Tekanan Waktu, Prosedur Review Dan Kontrol Kualitas, Komitmen Profesional, Dan External Locus Of Control Terhadap Penghentian Prematur Atas Prosedur Audit"

\section{Kerangka Teoritis}

\section{Pengaruh Tekanan Waktu Terhadap} Penghentian Prematur Atas Prosedur Audit

Tekanan waktu yang diberikan kepada auditor bertujuan untuk mengurangi biaya audit karena semakin cepat waktu pengerjaan audit maka biaya audit akan semakin kecil (Safriliana dkk., 2016). Jika auditor semakin cepat dalam menyelesaikan audit, maka biaya pelaksanaan penugasan audit akan semakin sedikit. Keadaan tersebut memberikan kemungkinan auditor melakukan tingkat penghentian prematur atas prosedur audit.

$\mathrm{H}_{1}$ : Tekanan waktu berpengaruh terhadap penghentian prematur atas prosedur audit.

Jika seorang auditor semakin berkomitmen terhadap profesinya dan selalu menjaga integritasnya, maka auditor tersebut akan berpikir untuk melakukan hal tersebut, karena akan mencoreng integritas dan profesionalnya apalagi jika diketahui oleh rekannya. Hal tersebut menunjukkan bahwa terdapat hubungan antara komitmen profesional dengan penerimaan terhadap perilaku pengurangan kualitas audit.

$\mathrm{H}_{3}$ : Komitmen profesional berpengaruh terhadap penghentian prematur atas prosedur audit.
Pengaruh Prosedur Review Dan

Kontrol Kualitas Terhadap

Penghentian Prematur Atas Prosedur Audit

Dalam penelitian yang dilakukan oleh Nurhardianty (2016) menunjukkan bahwa auditor yang yang memiliki prosedur review dan kontrol kualitas yang tinggi pada hasil audit, maka mereka akan memperkecil probabilitas mereka dalam menghentikan prematur prosedur audit. Berdasarkan penelitianpenelitian sebelumnya, pendeteksian akan adanya penghentian prematur atas prosedur audit oleh Kantor Akuntan Publik melalui prosedur review dan kontrol kualitas akan membuat auditor berpikir dua kali ketika akan melakukan tindakan tersebut. Oleh karena itu, prosedur review dan kontrol kualitas oleh Kantor Akuntan Publik dapat menurunkan kemungkinan auditor melakukan penghentian prematur atas prosedur audit.

$\mathrm{H}_{2}$ : Prosedur review dan kontrol kualitas berpengaruh terhadap penghentian prematur atas prosedur audit.

Pengaruh Komitmen Profesional Terhadap Penghentian Prematur Atas Prosedur Audit

Komitmen profesional dapat menjadi faktor penyebab terjadinya penghentian prematur atas prosedur audit.

Pengaruh External Locus Of Control Terhadap Penghentian Prematur Atas Prosedur Audit

Lokus kendali seseorang akan mempengaruhi cara pandang mereka terhadap kondisi yang dihadapi. Auditor yang memiliki lokus kendali internal, cenderung memiliki motivasi kuat dalam penyelesaian masalah jika dibandingkan dengan seseorang yang memiliki lokus kendali eksternal, sedangkan auditor yang memiliki lokus kendali eksternal diduga cenderung melakukan penghentian prematur atas prosedur audit. 
$\mathrm{H}_{4}$ : External locus of control berpengaruh terhadap penghentian prematur atas prosedur audit.

\section{Metodologi Penelitian}

\section{Metode Penelitian}

Jenis penelitian ini adalah kuantitatif dengan menggunakan data primer dan metode pengumpulan data dengan cara survei. Survei ini dilakukan dengan cara mengedarkan kuesioner yang berisi beberapa pertanyaan dan pernyataan yang berkaitan dengan pengalaman dan keahlian auditor dalam bidang auditing yang berhubungan dengan variabel yang diteliti. Kemudian setiap responden diminta untuk memberikan jawaban atas pertanyaan dan penilaian atas pernyataan dalam kuesioner tersebut.

\section{Operasional Variabel}

Penghentian Prematur Atas Prosedur Audit

Penghentian prematur atas prosedur audit (premature sign off of audit procedure) adalah suatu praktik ketika auditor mendokumentasikan instrumen yang dikembangkan oleh Heriningsih (2002) dan digunakan dalam penelitian Wahyudi dkk., (2011). Variabel ini memiliki instrumen berupa 5 butir pertanyaan yang dijawab dengan menggunakan skala likert 1 sampai 5 poin dengan nilai terendah adalah 1 dan nilai tertinggi adalah 5. Skor 1 menunjukkan tekanan waktu yang rendah sedangkan skor 5 menunjukkan tekanan waktu yang tinggi.

\section{Prosedur Review dan Kontrol Kualitas}

Prosedur review dan kontrol kualitas merupakan proses memeriksa atau meninjau ulang pekerjaan untuk mengawasi terjadinya indikasi ketika auditor telah menyelesaikan tugasnya, padahal tugas yang disyaratkan tersebut gagal dilakukan (Weningtyas dkk., dalam Wahyudi dkk., 2011). Variabel prosedur review dan kontrol kualitas diukur menggunakan instrumen yang prosedur audit secara lengkap tanpa benar-benar melakukannya atau mengabaikannya atau tidak melakukan beberapa prosedur audit yang disyaratkan tetapi ia dapat memberi opini atas suatu laporan keuangan (Shapeero et al., 2003 dalam Wahyudi dkk., 2011). Instrumen yang digunakan untuk mengukur penghentian prematur atas prosedur audit didasarkan atas instrumen yang digunakan dalam penelitian Alderman and Deitrick (1982) dan digunakan dalam penelitian Wahyudi dkk., (2011). Variabel ini memiliki instrumen berupa 10 butir pertanyaan dan diukur menggunakan skala likert 5 poin dengan nilai terendah adalah 1 dan nilai tertinggi adalah 5 .

\section{Tekanan Waktu}

Tekanan waktu atau time pressure adalah suatu keadaan dimana auditor mendapatkan tekanan dari Kantor Akuntan Publik tempatnya bekerja untuk menyelesaikan audit pada waktu dan anggaran biaya yang telah ditentukan sebelumnya (Wahyudi dkk., 2011). Variabel tekanan waktu diukur menggunakan

dikembangkan oleh Malone and Roberts (1996) dan digunakan dalam penelitian Wahyudi dkk., (2011). Variabel ini memiliki instrumen berupa 6 butir pertanyaan yang dijawab dengan menggunakan skala likert 1 sampai 5 poin dengan nilai terendah adalah 1 dan nilai tertinggi adalah 5 .

\section{Komitmen Profesional}

Komitmen profesional dapat dipersepsikan sebagai tingkat loyalitas individu pada profesinya seperti yang dipersepsikan oleh individu tersebut (Trisnaningsih, 2003). Seseorang yang profesional dalam pekerjaan, maka akan sedikit dicurigai melakukan penyimpangan seperti penghentian prematur atas prosedur audit (Nurhardianty, 2016). Variabel komitmen profesional diukur menggunakan instrumen yang dikembangkan oleh peneliti dengan menjadikan Prinsip Dasar 
Etika dalam Kode Etik Profesi Akuntan Publik sebagai acuan. Variabel ini memiliki instrumen berupa 5 butir pertanyaan yang dijawab dengan menggunakan skala likert 1 sampai 5 poin dengan nilai terendah adalah 1 dan nilai tertinggi adalah 5 .

\section{External Locus of Control}

Locus of control atau lokus kendali mengacu pada sejauh mana individu meyakini bahwa ia dapat mengendalikan faktor-faktor yang mempengaruhi dirinya (Martini, 2017). Auditor yang memiliki lokus kendali eksternal diduga cenderung melakukan penghentian prematur atas prosedur audit. Dalam penelitian ini locus of control yang digunakan adalah locus of control eksternal karena auditor yang memiliki lokus kendali eksternal diduga

Kantor Akuntan Publik yang berada di Jakarta Selatan. Auditor sebagai responden adalah auditor dengan jabatan senior auditor, supervisor, manajer, dan partner dengan pengalaman bekerja minimal 2 tahun.

\section{Teknik Pengumpulan Data}

Jenis data yang digunakan dalam penelitian ini adalah data primer. Sumber data penelitian diperoleh dari jawaban atas kuesioner yang dibagikan kepada responden. Metode pengumpulan data dalam penelitian ini dengan metode survei. Survei ini dilakukan dengan cara mengedarkan kuesioner ke kantor akuntan publik. Kuesioner tersebut berisi beberapa pertanyaan dan pernyataan yang berkaitan dengan pengalaman dan keahlian auditor dalam bidang auditing yang berhubungan dengan variabel yang diteliti. Kemudian setiap responden diminta untuk memberikan jawaban atas pertanyaan dan penilaian atas pernyataan dalam kuesioner tersebut.

\section{Analisis Data}

Analisis data penelitian ini menggunakan teknik statistik untuk menunjukkan hasil dari kuisioner pada masing-masing pertanyaan atau cenderung melakukan penghentian prematur atas prosedur audit. Variabel locus of control diukur menggunakan instrumen yang dikembangkan oleh Spector (1982) dan digunakan dalam penelitian Damayanti (2017). Variabel ini memiliki instrumen berupa 6 butir pertanyaan yang dijawab dengan menggunakan skala likert 1 sampai 5 poin dengan nilai terendah adalah 1 dan nilai tertinggi adalah 5 .

\section{Populasi dan Sampel}

Populasi dari penelitian ini adalah auditor yang bekerja pada kantor akuntan publik di Jakarta Selatan yang terdaftar di Institut Akuntan Publik Indonesia (IAPI) tahun 2018. Sampel dari penelitian ini ditentukan dengan purposive sampling. Sampel yang digunakan dalam penelitian ini adalah 16 pernyataan terhadap variabel yang ada didalamnya, teknik yang digunakan antara lain:

\section{Statistik Deskriptif}

Statistik deskriptif merupakan statistik yang menggambarkan fenomena atau karakteristik dari data yang menyediakan nilai frekuensi, pengukur tendensi pusat (Jogiyanto, 2012). Dengan demikian dalam penelitian ini, statistik deskriptif digunakan untuk memberikan gambaran mengenai demografi responden penelitian yang terdiri dari $\mathrm{min}$ (nilai minimal), $\max$ (nilai maksimal), mean (rata-rata frekuensi), serta standar deviasi yang mengukur rata-rata penyimpangan masing-masing item data terhadap nilai yang diharapkan.

\section{Uji Kualitas Data}

Penelitian ini menggunakan pengumpulan data dengan kuesioner sehingga kualitas kuesioner yang merupakan kesungguhan responden dalam menjawab pertanyaan maupun pernyataan dan faktor situasional menjadi sangat penting. Oleh karena itu dalam penelitian ini diperlukan uji reliabilitas dan uji validitas. 


\section{Uji Validitas}

Validitas menunjukkan seberapa nyata suatu pengujian mengukur apa yang seharusnya diukur (Jogiyanto, 2012). Uji validitas mengukur apakah alat ukur dapat mencapai sasaran dan tujuan penelitian dengan benar dan nyata. Uji validitas pada penelitian ini dilakukan dengan menghitung korelasi antara skor masing-masing butir pertanyaan dengan total skor pertanyaan. Kriteria yang digunakan valid atau tidak valid adalah apabila koefisien korelasi $\mathrm{r}$ hitung kurang dari nilai $r_{\text {tabel }}$ dengan tingkat signifikansi lebih dari $5 \%$ berarti butir pertanyaan tersebut tidak valid (Ghozali, 2011).

\section{Uji Reliabilitas}

Reliabilitas berhubungan dengan konsistensi dari suatu pengukur (Jogiyanto, 2012). Suatu pengukur dikatakan reliabel atau dapat diandalkan jika akurat dan konsisten. Pengujian ini dilakukan untuk menghitung koefisien Cronbach Alpha dari masing-masing instrumen dalam suatu variabel. Instrumen dapat dikatakan handal (reliable) bila mempunyai koefisien Cronbach Alpha lebih dari 0,7 (Ghozali, 2011). Hasil uji reliabilitas kuesioner sangat tergantung pada kesungguhan responden dalam menjawab semua item pertanyaan penelitian.

\section{Uji Asumsi Klasik}

Uji asumsi klasik yang digunakan dalam penelitian ini terdiri dari uji normalitas, uji multikolinieritas, dan uji heteroskedestisitas.

\section{Uji Normalitas}

Uji normalitas dilakukan untuk mengetahui apakah variabel dependen dan variabel independen mempunyai distribusi normal, dengan melihat normalitas probabilitas plot yang membedakan distribusi kumulatif dari data sesungguhnya dengan distribusi kumulatif dan distribusi normal. Model regresi yang baik adalah model regresi yang mempunyai distribusi normal atau mendekati normal (Ghozali, 2011).
Metode yang digunakan dalam penelitian ini untuk mendeteksi residual berdistribusi normal atau tidak adalah dengan uji Kolmogorov-Smirnov (K-S) yang membandingkan antara data yang diuji normalitasnya dengan data normal baku. Jika probabilitas kurang dari 0,05 atau $5 \%$ berarti data tersebut berdistribusi tidak normal. Sebaliknya jika probabilitas lebih dari 0,05 atau $5 \%$ maka data tersebut berdistribusi normal. Selain itu, uji normalitas juga dapat dilihat dari grafik histogram dan grafik normal probability plot (P-P plot). Data dikatakan terdistribusi normal jika data menyebar disekitar garis diagonal dan mengikuti arah garis diagonal atau grafik histogramnya.

\section{Uji Multikolinieritas}

Uji multikolinieritas digunakan untuk menguji apakah terdapat korelasi antar variabel independen dalam model regresi. Model regresi yang baik seharusnya tidak terjadi korelasi antarvariabel independen (Ghozali, 2011). Uji multikolinieritas dapat dideteksi dengan cara melihat nilai tolerance dan nilai VIF (Variance Inflation Factor). Jika nilai VIF ada disekitar angka 1 dan nilai tolerance mendekati angka 1 pada kolom Collinearity Statistic dalam tabel coefficients, maka tidak terjadi multikolinearitas. Multikolinearitas terjadi jika nilai VIF melebihi 10 , jika nilai VIF kurang dari 10 maka korelasi antarvariabel independen masih bisa ditolerir.

\section{Uji Heteroskedestisitas}

Uji heteroskedestisitas digunakan untuk mengetahui apakah dalam sebuah regresi terjadi ketidaksamaan varian dari residual satu pengamatan ke pengamatan yang lain. Jika varians dari residual satu pengamatan ke pengamatan lain tetap maka disebut homoskedestisitas, sedangkan jika berbeda disebut heteroskedestisitas. Dalam Ghozali (2011), model regresi yang baik adalah 
yang homoskedestisitas atau tidak terjadi heteroskedestisitas.

Dalam penelitian ini, pengujian ada tidaknya heteroskedestisitas dilakukan dengan melihat grafik Scatterplot antara nilai prediksi variabel dependen yaitu ZPRED dengan residualnya yaitu SRESID. Jika ada pola tertentu yang teratur, maka telah terjadi heteroskedestisitas. Sebaliknya jika tidak ada pola yang jelas serta titik-titik menyebar maka tidak terjadi heteroskedestisitas.

\section{Uji Hipotesis}

Uji hipotesis menggunakan dua metode pengujian, yaitu:

\section{Uji Regresi Linear Berganda}

Pengujian yang dilakukan dalam penelitian ini menggunakan analisis regresi dimana analisis ini digunakan untuk mengukur pengaruh antara variable bebas terhadap variabel terikat. Persamaan dari analisis regresi ini, yaitu:

$\boldsymbol{Y}=\boldsymbol{a}+\boldsymbol{b} \boldsymbol{X}_{1}+\boldsymbol{b} \boldsymbol{X}_{2}+\boldsymbol{b} \boldsymbol{X}_{3}+\boldsymbol{b} \boldsymbol{X}_{4}+\boldsymbol{e}$

Dimana:

$\mathrm{Y}=$ Penghentian prematur atas prosedur audit

$a=$ Konstanta

$b=$ Koefisien regresi

$X_{1}=$ Tekanan waktu

$X_{2}=$ Prosedur review dan kontrol

kualitas

$X_{3}=$ Komitmen profesional

$X_{4}=$ External locus of control

$e=$ error

\section{Uji Goodness-Of-Fit-Test}

Uji Goodness of Fit atau uji kelayakan model digunakan untuk mengukur ketepatan fungsi regresi sampel dalam menaksir nilai aktual. Secara statistik uji Goodness of Fit dapat dilakukan melalui pengukuran nilai koefisien determinasi, nilai statistik $\mathrm{F}$ dan nilai statistik t. Menurut Ghozali (2011), perhitungan statistik disebut signifikan secara statistik apabila nilai uji statistiknya berada dalam daerah kritis (daerah dimana Ho ditolak). Sebaliknya perhitungan statistik disebut tidak signifikan apabila nilai uji statistiknya berada dalam daerah dimana Ho diterima. Uji Goodness of Fit yang digunakan dalam penelitian ini adalah uji $\mathrm{t}$, uji F, dan uji koefisien determinasi.

\section{Uji t}

Pengujian hipotesis secara parsial (individu) dengan menggunakan uji $\mathrm{t}$ dilakukan untuk membuktikan apakah variabel independen secara parsial memiliki pengaruh signifikan terhadap variabel dependen (Ghozali, 2011). Cara melakukan uji $t$ yaitu dengan membandingkan nilai statistik $t$ hitung dengan titik kritis menurut tabel. Apabila nilai statistik $t$ hitung lebih besar dibandingkan $\mathrm{t}$ tabel, maka hipotesis alternatif (Ha) diterima. Selain itu, uji ini dapat dilakukan dengan kriteria 1) Jika nilai signifikansi > 0,05 (5\%) maka Ho diterima dan Ha ditolak, maka tidak ada pengaruh variabel independen secara individual terhadap variabel dependen. 2) Jika nilai signifikansi $<0,05(5 \%)$ maka Ha diterima dan Ho ditolak, maka variabel independen secara individual mempengaruhi variabel dependen.

\section{Uji F}

Uji $F$ digunakan untuk menguji keberadaan besarnya pengaruh variabel independen secara simultan atau bersama-sama terhadap variabel dependen. Kriteria pengujian yang digunakan adalah jika probability value ( $p$ value $)<0,05$, maka Ha diterima dan jika $\mathrm{p}$ value $>0,05$, maka Ha ditolak. Uji $F$ dapat pula dilakukan dengan membandingkan nilai $\mathrm{F}_{\text {hitung }}$ dengan $\mathrm{F}_{\text {tabel }}$. Dengan dasar pengambilan keputusan: 1) Jika $\mathrm{F}_{\text {hitung }}<\mathrm{F}_{\text {tabel }}$ dan probabilitas signifikansi $>0,05$ maka semua variabel independen secara bersama-sama tidak berpengaruh terhadap variabel dependen. 2) Jika $F_{\text {hitung }}>F_{\text {tabel }}$ dan probabilitas signifikansi $<0,05$ maka semua variabel independen secara bersama-sama berpengaruh terhadap variabel dependen. 


\section{Uji Koefisien Determinasi}

Koefisien determinasi berganda menyatakan seberapa baik suatu model untuk menjelaskan variasi variabel dependen (Ghozali, 2011). Nilai Adjusted $R$ Square $\left(\mathrm{R}^{2)}\right.$ yang semakin tinggi menunjukkan bahwa semakin kuat variabel independen menjelaskan variabel dependen. Sebaliknya, semakin kecil nilai Adjusted $R$ Square menunjukkan semakin rendah kemampuan variabel independen untuk menjelaskan variabel dependen. Hal-hal yang perlu diperhatikan dalam koefisien determinasi berganda adalah 1) Jika $\mathrm{R}^{2}=$ 1 , maka terdapat pengaruh sempurna antara variabel independen terhadap variabel dependen. 2) Jika $R^{2}=0$, maka tidak terdapat pengaruh antara variabel independen terhadap variabel dependen. 3) Jika $R^{2}$ mendekati 1, maka terdapat pengaruh antara variabel independen terhadap variabel dependen.

\section{Hasil Penelitian dan Pembahasan}

\section{Statistik Deskriptif}

Tabel 1

Statistik Deskriptif

\begin{tabular}{|c|c|c|c|c|c|c|}
\hline \multicolumn{7}{|c|}{ Statistics } \\
\hline & & PPPA & $\begin{array}{r}\text { Tekanan } \\
\text { Waktu }\end{array}$ & $\begin{array}{r}\text { Prosedur } \\
\text { Review }\end{array}$ & $\begin{array}{r}\text { Komitmen } \\
\text { Profesional }\end{array}$ & $\begin{array}{r}\text { External } \\
\text { Locus } \\
\text { of Control }\end{array}$ \\
\hline \multirow[t]{2}{*}{$\mathrm{N}$} & Valid & 109 & 109 & 109 & 109 & 109 \\
\hline & Missing & 0 & 0 & 0 & 0 & 0 \\
\hline & Mean & 28,36 & 19,71 & 21,66 & 20,56 & 21,44 \\
\hline Std. & Deviation & 9,765 & 3,816 & 5,682 & 3,583 & 5,322 \\
\hline & Range & 35 & 15 & 20 & 14 & 20 \\
\hline & Minimum & 10 & 10 & 10 & 11 & 10 \\
\hline & Maximum & 45 & 25 & 30 & 25 & 30 \\
\hline
\end{tabular}

Sumber: SPSS versi 24.0 for windows

Variabel penghentian prematur atas prematur audit memiliki nilai terendah sebesar 10 dan nilai tertinggi sebesar 45 dengan nilai rata-rata (mean) sebesar 28,36, standar deviasi 9,765, dan nilai range sebesar 35 . Variabel tekanan waktu memiliki nilai minimum sebesar 10 dan maksimum sebesar 25 dengan rata-rata (mean) sebesar 19,71, standar deviasi sebesar 3,816, dan nilai range sebesar 15. Variabel prosedur review dan kontrol kualitas memiliki nilai minimum sebesar 10 dan maksimum sebesar 30 dengan rata-rata (mean) sebesar 21,66, standar deviasi sebesar 5,682, dan nilai range sebesar 20. Variabel komitmen profesional memiliki nilai minimum sebesar 11 dan maksimum sebesar 25 dengan rata-rata (mean) sebesar 20,56, standar deviasi sebesar 3,583, dan nilai range sebesar 14. Variabel external locus of control memiliki nilai minimum sebesar 10 dan maksimum sebesar 30 dengan rata-rata (mean) sebesar 21,44, standar deviasi sebesar 5,322, dan nilai range sebesar 20 . 
Hasil Uji validitas

Tabel 2

Hasil Uji Validitas Variabel (Y)

Penghentian Prematur Atas Prosedur Audit

\begin{tabular}{|c|c|c|c|}
\hline Item & $\mathbf{r}_{\text {hitung }}$ & $\mathbf{r}_{\text {tabel }}$ & Keterangan \\
\hline Item 1 & 0,826 & 0,1882 & Valid \\
\hline Item 2 & 0,847 & 0,1882 & Valid \\
\hline Item 3 & 0,843 & 0,1882 & Valid \\
\hline Item 4 & 0,842 & 0,1882 & Valid \\
\hline Item 5 & 0,837 & 0,1882 & Valid \\
\hline Item 6 & 0,860 & 0,1882 & Valid \\
\hline Item 7 & 0,775 & 0,1882 & Valid \\
\hline Item 8 & 0,810 & 0,1882 & Valid \\
\hline Item 9 & 0,818 & 0,1882 & Valid \\
\hline Item 10 & 0,794 & 0,1882 & Valid \\
\hline
\end{tabular}

Sumber: Data primer yang diolah, 2018

Tabel 3

Hasil Uji Validitas Variabel $\left(\mathbf{X}_{1}\right)$

Tekanan Waktu

\begin{tabular}{|c|c|c|c|}
\hline Item & $\mathbf{r}_{\text {hitung }}$ & $\mathbf{r}_{\text {tabel }}$ & Keterangan \\
\hline Item 1 & 0,762 & 0,1882 & Valid \\
\hline Item 2 & 0,779 & 0,1882 & Valid \\
\hline Item 3 & 0,764 & 0,1882 & Valid \\
\hline Item 4 & 0,822 & 0,1882 & Valid \\
\hline Item 5 & 0,735 & 0,1882 & Valid \\
\hline
\end{tabular}

Sumber : data primer yang diolah, 2018

Tabel 4

Hasil Uji Validitas Variabel $\left(\mathbf{X}_{2}\right)$

Prosedur Review dan Kontrol Kualitas

\begin{tabular}{|c|c|c|c|}
\hline Item & $\mathbf{r}_{\text {hitung }}$ & $\mathbf{r}_{\text {tabel }}$ & Keterangan \\
\hline Item 1 & 0,807 & 0,1882 & Valid \\
\hline Item 2 & 0,851 & 0,1882 & Valid \\
\hline Item 3 & 0,865 & 0,1882 & Valid \\
\hline Item 4 & 0,851 & 0,1882 & Valid \\
\hline Item 5 & 0,877 & 0,1882 & Valid \\
\hline Item 6 & 0,776 & 0,1882 & Valid \\
\hline
\end{tabular}

Sumber: Data primer yang diolah, 2018 
Tabel 5

Hasil Uji Validitas Variabel $\left(\mathbf{X}_{\mathbf{3}}\right)$

Komitmen Profesional

\begin{tabular}{|c|c|c|c|}
\hline Item & $\mathbf{r}_{\text {hitung }}$ & $\mathbf{r}_{\text {tabel }}$ & Keterangan \\
\hline Item 1 & 0,779 & 0,1882 & Valid \\
\hline Item 2 & 0,805 & 0,1882 & Valid \\
\hline Item 3 & 0,807 & 0,1882 & Valid \\
\hline Item 4 & 0,807 & 0,1882 & Valid \\
\hline Item 5 & 0,777 & 0,1882 & Valid \\
\hline
\end{tabular}

Sumber: Data primer yang diolah, 2018

Tabel 6

Hasil Uji Validitas Variabel $\left(\mathbf{X}_{\mathbf{4}}\right)$

External Locus of Control

\begin{tabular}{|c|c|c|c|}
\hline Item & $\mathbf{r}_{\text {hitung }}$ & $\mathbf{r}_{\text {tabel }}$ & Keterangan \\
\hline Item 1 & 0,654 & 0,1882 & Valid \\
\hline Item 2 & 0,707 & 0,1882 & Valid \\
\hline Item 3 & 0,862 & 0,1882 & Valid \\
\hline Item 4 & 0,773 & 0,1882 & Valid \\
\hline Item 5 & 0,815 & 0,1882 & Valid \\
\hline Item 6 & 0,777 & 0,1882 & Valid \\
\hline
\end{tabular}

Sumber: Data primer yang diolah, 2018

Berdasarkan hasil tabel di atas menunjukkan bahwa seluruh indikator pada variabel independen maupun dependen mempunyai nilai validitas lebih besar dari $r_{\text {tabel }}$ yaitu 0,1882 sehingga seluruh item variabel dinyatakan valid dan dapat dipakai untuk melakukan penelitian selanjutnya.

\section{Hasil Uji Reliabilitas}

Tabel 7

Hasil Uji Reliabilitas

\begin{tabular}{|l|c|c|}
\hline \multicolumn{1}{|c|}{ Variabel } & Cronbach Alpha & Keterangan \\
\hline PPPA & 0,961 & Reliabel \\
\hline Tekanan Waktu & 0,909 & Reliabel \\
\hline Prosedur Review & 0,946 & Reliabel \\
\hline Komitmen Profesional & 0,921 & Reliabel \\
\hline External LOC & 0,915 & Reliabel \\
\hline
\end{tabular}

Sumber : data primer yang diolah, 2018 
Berdasarkan tabel di atas diperoleh nilai Cronbach Alpha untuk seluruh variabel lebih dari 0,70 artinya seluruh variabel dinyatakan reliabel sehingga dapat digunakan dalam penelitian.

\section{Hasil Uji Normalitas}

Tabel 8

Hasil Uji Statistik Kolmogorov-Smirnov (K-S)

\begin{tabular}{|l|r|r|}
\hline \multicolumn{2}{|c|}{ One-Sample Kolmogorov-Smirnov Test } \\
\hline \multicolumn{2}{|c|}{} & $\begin{array}{r}\text { Unstandardized } \\
\text { Predicted Value }\end{array}$ \\
\hline \multicolumn{2}{|c|}{ N } & 109 \\
\hline Normal Parameters $^{\mathrm{a}, \mathrm{b}}$ & Mean & 28,3577982 \\
\cline { 2 - 3 } & Std. Deviation & 7,81187629 \\
\hline Most Extreme Differences & Absolute &, 070 \\
\cline { 2 - 3 } & Positive &, 070 \\
\cline { 2 - 3 } & Negative &,- 056 \\
\hline \multicolumn{2}{|c|}{ Asymp. Sig. (2-tailed) } \\
\hline \multicolumn{2}{|c|}{} \\
\hline a. Test distribution is Normal. \\
\hline b. Calculated from data. \\
\hline c. Lilliefors Significance Correction. \\
\hline d. This is a lower bound of the true significance. \\
\hline Sumber: SPSS versi 24.0 for windows
\end{tabular}

Sumber: SPSS versi 24.0 for windows

Tabel diatas menampilkan hasil uji statistik K-S dengan nilai regresi sebesar 0,070 dan nilai signifikansi sebesar 0,200. Hal ini menunjukkan bahwa nilai signifikansi lebih besar dari 0,05 maka data dinyatakan terdistribusi secara normal.

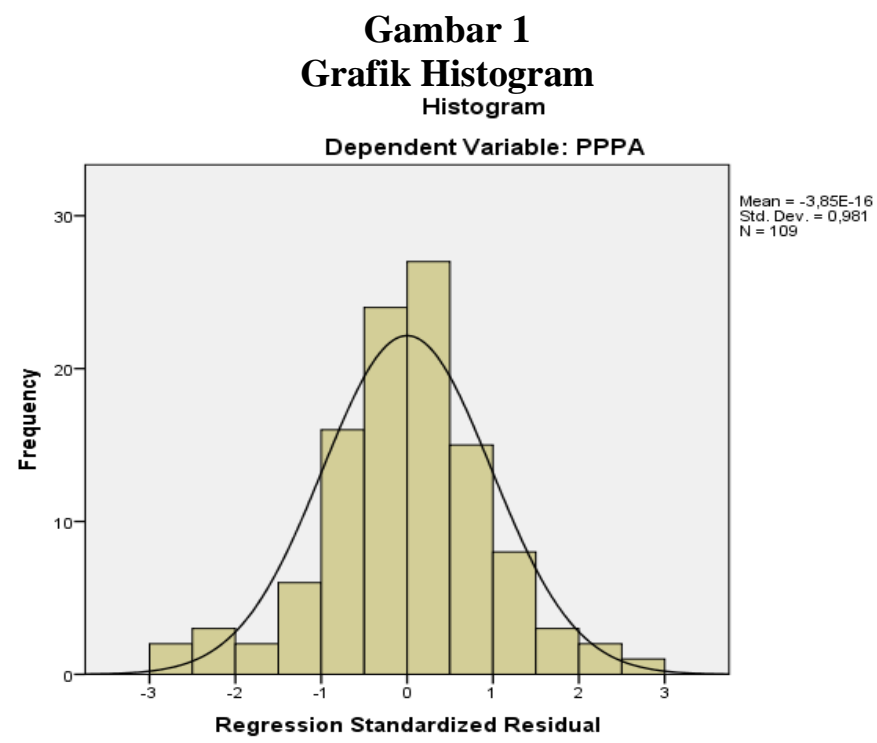

Sumber: SPSS versi 24.0 for windows

Gambar diatas menampilkan grafik histogram yang memiliki pola distribusi yang tidak terjadi menceng ke kiri maupun menceng ke kanan (mengikuti garis histogramnya). Maka data residual dinyatakan terdistribusi normal. 


\section{Gambar 2 \\ Grafik P-P Plot}

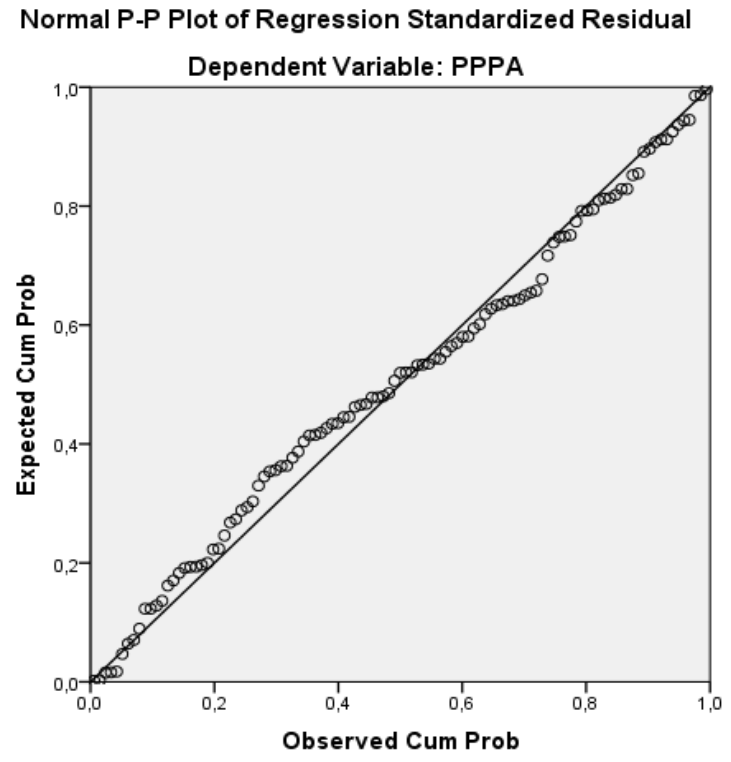

Sumber: SPSS versi 24.0 for windows

Gambar diatas menunjukkan bahwa data tersebut menunjukkan pola distribusi yang normal. Hal ini ditunjukkan oleh tampilan grafik P-P plot yang memperlihatkan bahwa titik-titik tersebar disekitar garis diagonal, serta penyebarannya mengikuti arah garis diagonal. Maka model regresi dinyatakan memenuhi asumsi normalitas.

\section{Hasil Uji Multikolinearitas}

Tabel 9

Hasil Uji Multikolinearitas

\begin{tabular}{|c|l|r|r|}
\hline \multicolumn{4}{|c|}{ Coefficients $^{\mathbf{a}}$} \\
\hline \multirow{2}{*}{ Model } & \multicolumn{2}{|c|}{ Collinearity Statistics } \\
\cline { 2 - 4 } & Tolerance & \multicolumn{1}{c|}{ VIF } \\
\hline \multirow{2}{*}{1} &, 361 & 2,770 \\
\cline { 2 - 4 } & Tekanan Waktu &, 459 & 2,180 \\
\cline { 2 - 4 } & Prosedur Review &, 445 & 2,249 \\
\cline { 2 - 4 } & Komitmen Profesional &, 289 & 3,464 \\
\cline { 2 - 4 } & External Locus of Control & \multicolumn{2}{|c}{ a. Dependent Variable: PPPA } \\
\hline \multicolumn{2}{|c|}{} \\
\hline
\end{tabular}

Sumber: SPSS versi 24.0 for windows

Tabel diatas menunjukkan bahwa nilai tolerance setiap variabel lebih besar dari 0,1 dan nilai Variance Inflation tekanan waktu, prosedur review dan kontrol kualitas, komitmen profesional, dan external locus of control.
Factor (VIF) adalah kurang dari 10. Maka dapat dinyatakan bahwa tidak terdapat multikolinearitas pada variabel 


\section{Hasil Uji Heteroskedestisitas}

Gambar 3

\section{Hasil Uji Heteroskedestisitas Menggunakan Scatterplot}

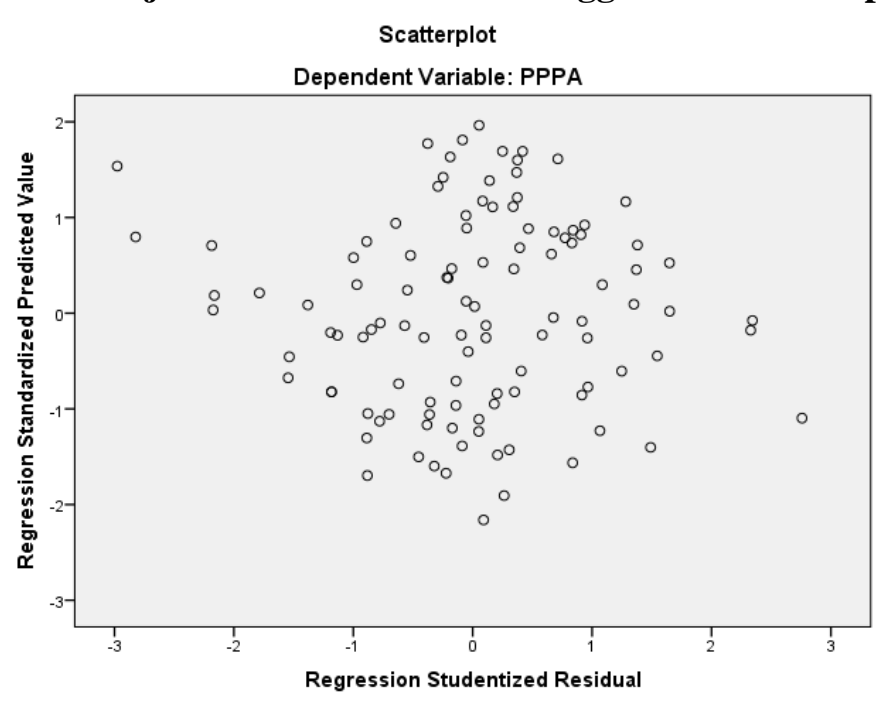

Sumber: SPSS versi 24.0 for windows

Gambar diatas menunjukkan bahwa grafik scatterplot memperlihatkan titik-titik yang menyebar secara acak di atas maupun di bawah angka 0 pada sumbu $\mathrm{Y}$ dan disisi kiri maupun disisi kanan angka 0 pada sumbu $\mathrm{X}$ dan penyebaran titik-titik data tidak membentuk suatu pola. Maka dapat dinyatakan bahwa tidak terjadi heteroskedestisitas pada model regresi.

Hasil Uji Hipotesis

Hasil Uji Regresi Linear Berganda

Tabel 10

Hasil Uji Regresi Linear Berganda

\begin{tabular}{|c|c|c|c|c|c|c|}
\hline \multicolumn{7}{|c|}{ Coefficients $^{\mathrm{a}}$} \\
\hline \multirow{2}{*}{\multicolumn{2}{|c|}{ Model }} & \multicolumn{2}{|c|}{ Unstandardized Coefficients } & \multirow{2}{*}{$\begin{array}{l}\text { Standardized } \\
\text { Coefficients } \\
\text { Beta }\end{array}$} & \multirow[b]{2}{*}{$\mathrm{t}$} & \multirow{3}{*}{$\frac{\text { Sig. }}{0.33}$} \\
\hline & & $\mathrm{B}$ & Std. Error & & & \\
\hline & (Constant) & 19,482 & 9,030 & & 2,157 & \\
\hline & Tekanan Waktu &, 582 & ,251 & 227 & 2,321 &, 022 \\
\hline & Prosedur Review &,- 360 & ,149 &,- 210 & $-2,413$ &, 018 \\
\hline & Komitmen Profesional &,- 377 & ,240 &,- 138 & $-1,567$ &, 120 \\
\hline & External LOC & 605 & 201 & ,330 & 3,010 & 003 \\
\hline
\end{tabular}

a. Dependent Variable: PPPA

Sumber: SPSS versi 24.0 for windows

Berdasarkan tabel diatas, maka persamaan regresi yang dapat dibentuk adalah sebagai berikut

$$
Y=19,482+0,582 X_{1}-0,360 X_{2}-0,377 X_{3}+0,605 X_{4}+e
$$




\section{Hasil Uji t}

Tabel 11

Hasil Uji t

\begin{tabular}{|l|c|c|c|c|}
\hline \multicolumn{1}{|c|}{ Variabel } & $\mathbf{t}_{\text {hitung }}$ & $\mathbf{t}_{\text {tabel }}$ & Signifikansi & Keterangan \\
\hline (Constant) & 2,157 & 1,983 & 0,033 & \\
\hline Tekanan Waktu & 2,321 & 1,983 & 0,022 & Signifikan \\
\hline Prosedur Review & $-2,413$ & 1,983 & 0,018 & Signifikan \\
\hline Komitmen Profesional & $-1,567$ & 1,983 & 0,120 & Tidak Signifikan \\
\hline External LOC & 3,010 & 1,983 & 0,003 & Signifikan \\
\hline
\end{tabular}

Sumber: Data primer yang diolah, 2018

Variabel tekanan waktu memiliki nilai $t_{\text {hitung }}$ lebih besar dari $t_{\text {tabel }}$ yakni sebesar 2,321>1,983 dengan tingkat signifikansi lebih kecil dari tingkat kesalahan, yakni sebesar 0,022 <0,05. Maka $\mathrm{H}_{1}$ diterima atau tekanan waktu berpengaruh terhadap penghentian prematur atas prosedur audit.

Variabel prosedur review dan kontrol kualitas memiliki nilai $t_{\text {hitung }}$ lebih kecil dari $t_{\text {tabel }}$ yakni sebesar $-2,413<$ 1,983 dengan tingkat signifikansi lebih kecil dari tingkat kesalahan, yakni sebesar $0,018<0,05$. Maka $\mathrm{H}_{2}$ diterima atau prosedur review dan kontrol kualitas berpengaruh terhadap penghentian prematur atas prosedur audit.

Variabel komitmen profesional memiliki nilai $t_{\text {hitung }}$ lebih kecil dari $t_{\text {tabel }}$ yakni sebesar $-1,567<1,983$ dengan tingkat signifikansi lebih tinggi dari tingkat kesalahan, yakni sebesar $0,120>$ 0,05 . Maka $\mathrm{H}_{3}$ ditolak atau komitmen profesional tidak berpengaruh terhadap penghentian prematur atas prosedur audit.

Variabel external locus of control memiliki nilai $t_{\text {hitung }}$ lebih besar dari $t_{\text {tabel }}$ yakni sebesar 3,010>1,983 dengan tingkat signifikansi lebih kecil dari tingkat kesalahan, yakni sebesar $0,003<$ 0,05 . Maka $\mathrm{H}_{4}$ diterima atau external locus of control berpengaruh terhadap penghentian prematur atas prosedur audit.

\section{Hasil Uji F}

Tabel 12

Hasil Uji F

\begin{tabular}{|l|l|r|r|r|r|c|}
\hline \multicolumn{7}{|c|}{ ANOVA $^{\text {a }}$} \\
\hline \multicolumn{2}{|l|}{ Model } & Sum of Squares & Df & Mean Square & F & Sig. \\
\hline \multirow{3}{*}{1} & Regression & 6590,744 & 4 & 1647,686 & 46,210 &, $000^{\text {b }}$ \\
\cline { 2 - 7 } & Residual & 3708,301 & 104 & 35,657 & & \\
\cline { 2 - 7 } & Total & 10299,046 & 108 & & & \\
\hline \multicolumn{2}{|l|}{ a. Dependent Variable: PPPA } \\
b. Predictors: (Constant), External Locus of Control, Prosedur Review, Komitmen \\
Profesional, Tekanan Waktu
\end{tabular}

\section{Sumber: SPSS versi 24.0 for windows}

Tabel diatas menunjukkan bahwa nilai $\mathrm{F}_{\text {hitung }}$ lebih besar dari nilai $\mathrm{F}_{\text {tabel }}$ yakni sebesar $46,210>2,459$ dan tingkat signifikansi lebih kecil dari tingkat kesalahan yakni sebesar $0,000<$ 0,05. Maka Ha diterima atau tekanan waktu, prosedur review dan kontrol kualitas, komitmen profesional, dan external locus of control berpengaruh secara simultan (bersama-sama) terhadap penghentian prematur atas prosedur audit. Hal ini membuktikan bahwa $\mathrm{H}_{5}$ diterima. 


\section{Hasil Uji Koefisien Determinasi}

Tabel 13

Hasil Uji Koefisien Determinasi

\begin{tabular}{|c|r|r|r|r|}
\hline \multicolumn{5}{|c|}{ Model Summary } \\
\hline Model & $\mathrm{R}$ & R Square & $\begin{array}{c}\text { Adjusted R } \\
\text { Square }\end{array}$ & $\begin{array}{c}\text { Std. Error of the } \\
\text { Estimate }\end{array}$ \\
\hline &, $800^{\mathrm{a}}$ &, 640 &, 626 & 5,971 \\
\hline
\end{tabular}

a. Predictors: (Constant), External Locus of Control, Prosedur Review, Komitmen Profesional, Tekanan Waktu

b. Dependent Variable: PPPA

Sumber: SPSS versi 24.0 for windows

Tabel diatas menunjukkan nilai Adjusted R Square adalah sebesar 0,626. Hal ini menunjukkan bahwa kemampuan variabel tekanan waktu, prosedur review dan kontrol kualitas, komitmen profesional, dan external locus of control

\section{Kesimpulan, Saran dan Implikasi}

\section{Kesimpulan}

Hasil dari penelitian ini menunjukkan bahwa variabel tekanan waktu, prosedur review dan kontrol kualitas, serta external locus of control berpengaruh secara parsial terhadap penghentian prematur atas prosedur audit, sedangkan variabel komitmen profesional tidak berpengaruh secara parsial terhadap penghentian prematur atas prosedur audit. Secara simultan, hasil penelitian ini menunjukkan bahwa variabel tekanan waktu, prosedur review dan kontrol kualitas, komitmen profesional, dan external locus of control

Selain itu, peranan Kantor Akuntan Publik dalam melakukan pemilihan personil dalam penugasan audit, pelaksanaan training, pengawasan terhadap kinerja auditor, perencanaan prosedur dan evaluasi jangka waktu audit, serta penerapan prosedur review dan kontrol kualitas yang efektif sangat diharapkan agar praktik penghentian prematur atas prosedur audit dapat diminimalisir.

\section{Saran}

Penelitian ini memiliki beberapa keterbatasan, diantaranya adalah sampel dari penelitian ini adalah auditor yang dapat menjelaskan variabel penghentian prematur atas prosedur audit adalah sebesar 62,6\%, sedangkan sisanya sebesar $37,4 \%$ merupakan pengaruh faktor lain diluar penelitian ini.

berpengaruh terhadap penghentian prematur atas prosedur audit.

\section{Implikasi}

Penelitian ini menunjukkan bahwa interaksi antara karakteristik personal auditor dengan faktor eksternal yang diterima auditor akan mempengaruhi auditor dalam melakukan praktik penghentian prematur atas prosedur audit. Oleh karena itu auditor diharapkan lebih mempertimbangkan kualitas profesional dan independensi saat melaksanakan audit.

bekerja di KAP di Jakarta Selatan, faktor internal dan eksternal yang dianalisis dalam penelitian ini sangat terbatas, penelitian ini tidak menggunakan metode wawancara dan hanya menggunakan metode kuesioner, serta jangka waktu penyebaran kuesioner sangat terbatas yakni pada bulan Juli hingga Agustus 2018. Oleh karena itu, penelitian selanjutnya diharapkan agar memperluas lingkup sampel penelitian, dapat menambah variabel independen lainnya seperti resiko audit, materialitas, turnover intentions, dan self esteem in relation to ambition, dapat melakukan metode wawancara langsung terhadap auditor 
dan agar lebih memperhatikan jangka waktu penyebaran dan pengambilan kuesioner.

\section{Daftar Pustaka}

Arens, Alvin A., Elder, dan Beasley. 2008. Auditing dan Jasa Assurance Pendekatan Terintegrasi Jilid 1. Edisi 12. Jakarta: Erlangga

Andani, Ni Made Surya, I Made Mertha. 2014. "Pengaruh Tekanan Anggaran Waktu, Locus of Control dan Komitmen Profesional pada Perilaku Penurunan Kualitas Audit”. E-Jurnal Akuntansi Universitas Udayana 6.2 (2014):185-196, ISSN: 2302-8556

Coram, Paul, Juliana Ng, dan David R. Woodliff. 2004. "The Effect of Risk of Misstatement On The Propensity To Commit Reduced Audit Quality Acts Under Time Budget Pressure". Auditing: A Journal of Practice and Theory Vol. 23 No. 2, 159-167

Damayanti, Attalia Citra. 2017. "Pengaruh Faktor Internal Dan Eksternal Auditor Terhadap Perilaku Penghentian Prematur Atas Prosedur Audit (Studi Empiris Pada Kantor Akuntan Publik Di Yogyakarta Dan Semarang)". Fakultas Ekonomi Dan Bisnis Universitas Muhammadiyah. Yogyakarta

Donnely, David P., Jeffrey J. Q, and David. 2003. "Auditor Acceptance of Dysfunctional Audit Behavior : An Explanatory Model Using Audtors, Personal Characteristics. "Journal of Behavioral Research In Accounting", Vol. 15

Ghozali, Imam. 2011. Aplikasi Analisis Multivariate Dengan Program SPSS. Semarang: Badan Penerbit Universitas Diponegoro

http://iaiglobal.or.id/v03/files/file_publikasi/Pre sentasi Manual SPM(fero).pdf kode etik diakses tgl 29 Mei 2018

http://iapi-lib.com/directory-2018/\#p=55 diakses 7 Juni 2018 http://iapi.or.id diakses 6 Juni 2018

http://iapi.or.id/Iapi/detail/237 diakses 5 $\underline{\text { Juni } 2018}$

https://bisnis.tempo.co/read/845604/mitra -ernst-young-indonesia-didendarp-13-miliar-di-as/full\&view $=\mathrm{ok}$ diakses 25 Mei 2018

https://hepiprayudi.files.wordpress.com/2 $\underline{011 / 09 / k o d e-e t i k-p r o f e s i-a k u n t a n-}$ publik.pdf diakses tgl 4 Juni 2018

https://www.ojk.go.id/id/kanal/perbankan /data-dan statistik/Documents/Pages/DataKAP-Atau-AP-Sebagai-AuditorBank/Daftar\%20KAP AP Februar i_2017_Posisi\%208\%20Februari\% 202017.pdf diakses 6 Juni 2018

Jogiyanto, Hartono. 2012. Teori Portofolio dan Analisis Investasi, Edisi Kedelapan, BPFE, Yogyakarta

Martini, Ni Putu Riski. 2017. "Pengaruh Faktor Internal Dan Eksternal Pada Penghentian Prematur Atas Prosedur Audit”. E-Jurnal Ekonomi dan Bisnis Universitas Udayana 6.2 (2017): 675-700

Messier, Wiliam F., Glover, Steven M., dan Prawitt, Douglas F. 2006. Jasa Audit dan Assurance. Pendekatan Sistematis. Buku Satu Edisi 4. (Nuri Hinduan, Pentj). Jakarta: Salemba Empat

Mulyadi. 2002. Auditing (Pengauditan). Edisi Keenam. Buku Satu. Jakarta: Salemba Empat

Putri, Hartati Mulani. 2015. "Faktor yang Mempengaruhi Penghentian Prematur atas Prosedur Audit pada Kantor Akuntan Publik". Fakultas Ekonomi, Universitas UPI Y.A.I Jakarta. Vol. 4 No. 2 (2015): 136-158, ISSN: 2089-7219

Qurrahman, Taufik, Susfayetti, dan Andi Mirdah. 2012. "Pengaruh Time Pressure, Resiko Audit, Materialitas, Prosedur Review dan Kontrol Kualitas, Locus of Control serta Komitmen Profesional 
Terhadap Penghentian Prematur Atas Prosedur Audit (Studi Empiris pada KAP Palembang)". E-jurnal BINAR AKUNTANSI Vol.1 No.1 (2012): 23-32, ISSN: 2303-1522

Rosdiana, Mega. 2017. "Pengaruh Tekanan Waktu, Tindakan Supervisi, dan Locus of Control Terhadap Penghentian Prematur atas Prosedur Audit". Journal Of Accounting Science Vol. 1 No. 2 (2017): 119-142, EISSN 25483501

Safriliana, Retna, Nancy Indah Susanti Boreel. 2016. "Analisis FaktorFaktor Yang Mempengaruhi Penghentian Prematur Atas Prosedur Audit (Studi Empiris Auditor Kap Di Jawa Timur)". Jurnal Akuntansi Aktual, Vol. 3, Januari 2016, hlm. 226-235

Sari, Nurhardianty Kurnia. 2016. "Pengaruh Tekanan Waktu, Risiko Audit, Materialitas, Prosedur Review Dan Kontrol Kualitas, Komitmen Profesional, Dan Locus Of Control Terhadap Penghentian Prematur Atas Prosedur Audit (Survey pada Auditor di KAP Wilayah Pekanbaru, Medan, Batam, dan Padang)"., JOM Fekon Vol. 3 No. 1, Februari (2016): $1-15$

Sekaran, Uma. (2011). Research Methods for business Edisi I and 2. Jakarta: Salemba Empat

Sitorus, Maria F. 2017 "Pengaruh tekanan waktu, tindakan supervisi, prosedur review dan kontrol kualitas, dan komitmen profesional terhadap penghentian Prematur atas prosedur audit (Studi Empiris pada BPKP Perwakilan Riau dan Sumatera Utara)". JOM Fekon, Vol. 4 No. 1, Februari (2017): $967-$ 981

Sitorus, Santa Ulina. 2016. "Pengaruh Time Pressure, Audit Risk, Professional Commitment, Review
Procedure And Quality Control Dan Self Esteem In Relation To Ambition Terhadap Terjadinya Penghentian Prematur Atas Prosedur Audit(Premature Sign Off) (Studi Empiris pada Kantor Akuntan Publik Provinsi Riau, Padang dan Medan)". JOM Fekon, Vol. 3 No. 1, Februari (2016): 1051-1065

Sugiono, 2013, Metodologi Penelitian Kuantitatif, Kualitatif Dan $R \& D$. Bandung: Alfabeta

Trisnaningsih, T. 2003. "Pengaruh Komitmen Terhadap Kepuasan Kerja Auditor: Motivasi Sebagai Variabel Intervening (Studi Empiris Pada Kantor Akuntan Publik Di Jawa Timur)", Jurnal Riset Akuntansi Indonesia. No. 2 (6), 199-215

Wahyudi, Imam, Jurica Lucyanda, dan Loekman H. Suhud. 2011. "Praktik Penghentian Prematur Atas Prosedur Audit"., Vol. 1 No. 2, 125-140, ISSN 2088-2106

Wintari, Ni Wayan Wiwin Intan, I Made Sukartha, I Dewa Nyoman Badera. 2015. "Pengaruh Tekanan Anggaran Waktu, Locus Of Control Dan Komitmen Profesional Pada Perilaku Penurunan Kualitas Audit:. Jurnal Buletin Studi Ekonomi, Vol. 20 No. 2, Agustus (2015): 138-149

Wulandari, Abdul Aziz. 2015. "Pengaruh Tekanan Waktu, Tindakan Supervisi, dan Resiko Audit Terhadap Penghentian Prematur Atas Prosedur Audit”. Syariah Paper Accounting FEB UMS, Seminar Nasional dan The 2nd Call for Syariah Paper, hlm. 543551, ISSN 2460-0784

Yosua, Rikarbo Rekat. 2012. "FaktorFaktor yang Mempengaruhi Penghentian Prematur Atas Prosedur Audit: Studi Empiris Pada BPKP Riau”. 
Yusrawati dan Ari Suryadi. 2009. "Pengaruh Time Pressure, Risiko Audit, Materialitas,Prosedur Review Dan Kontrol Kualitas Serta LocusOf Control Terhadap Penghentian Prematur Atas Prosedur Audit Pada Kap Di Pekanbaru”. Universitas Islam Riau. Jurnal Eknomi, Manajemen dan Akuntansi. Vol. 15 No.1, Juni 2009. Hal.15-32 